University of South Florida

DIGITAL COMMONS

Digital Commons @ University of

@ UNIVERSITY OF SOUTH FLORIDA

South Florida

4-1986

\title{
Transient Electromagnetic Sounding for Groundwater
}

David V. Fitterman

U.S. Geological Survey

Mark T. Stewart

University of South Florida, mark@usf.edu

Follow this and additional works at: https://digitalcommons.usf.edu/gly_facpub

Part of the Geochemistry Commons, Geology Commons, and the Geophysics and Seismology Commons

\section{Scholar Commons Citation}

Fitterman, David V. and Stewart, Mark T., "Transient Electromagnetic Sounding for Groundwater" (1986). Geology Faculty Publications. 1.

https://digitalcommons.usf.edu/gly_facpub/1

This Article is brought to you for free and open access by the Geology at Digital Commons @ University of South Florida. It has been accepted for inclusion in Geology Faculty Publications by an authorized administrator of Digital Commons@ @niversity of South Florida. For more information, please contact digitalcommons@usf.edu. 


\title{
Transient electromagnetic sounding for groundwater
}

\author{
David V. Fitterman* and Mark T. Stewart
}

\begin{abstract}
ARSTRACT
The feasibility of using the transient electromagnetic sounding (TS or TDEM) method for groundwater exploration can be studied by means of numerical models. As examples of its applicability to groundwater exploration, we study four groundwater exploration problems: (1) mapping of alluvial fill and gravel zones over bedrock; (2) mapping of sand and gravel lenses in till; (3) detection of salt or brackish water interfaces in freshwater aquifers; and (4) determination of hydrostratigraphy. These groundwater problems require determination of the depth to bedrock; location of resistive, high-porosity zones associated with fresh water; determination of formation resistivity to assess water quality; and determination of lithology and geometry, respectively. The TS method is best suited for locating conductive targets, and has very good vertical resolution. Unlike other sounding techniques where the receiver-transmitter array must be expanded to sound more deeply, the depth of investigation for the TS method is a function of the length of time the transient is recorded. Present equipment limitations require that exploration targets with resistivities of $50 \Omega \cdot \mathrm{m}$ or more be at least $50 \mathrm{~m}$ deep to determine their resistivity. The maximum depth of exploration is controlled by the geoelectrical section and background electromagnetic (EM) noise. For a particular exploration problem, numerical studies are recommended to determine if the target is detectable.
\end{abstract}

\section{INTRODUCTION}

In many parts of the world, the Earth provides one of the most basic human needs - water for drinking, irrigation, and a myriad of daily uses. Because of water's great importance to life, fundamental questions about it are: where is it, how much of it is there, and what is its quality? At what rate can the resource be used without adverse effect? These are exploration and production questions which geophysical techniques can help to answer.

A variety of geophysical techniques have been successfully used for groundwater studies, including electrical methods
(Flathe, 1955; Zohdy, 1969, Flathe, 1970, Ogilvy, 1970; Zohdy, et al., 1974), seismic refraction (Levshin, 1961; Bonini and Hickok, 1969; Eaton and Watkins, 1970), and gravity surveys (Hall and Hajnal, 1962; Spangler and Libby, 1968; Carmichael and Henry, 1977). Of the electrical methods, de resistivity is the most commonly utilized because it is easy to use, the cost is low, and interpretational aids are available. Profiling electromagnetic (EM) techniques such as loop-loop frequency domain and VLF have been used often for mapping problems (Steward, 1982). These techniques are inexpensive and easy to use, but do not provide the quantitative information obtained from sounding techniques. Electromagnetic sounding techniques, on the other hand, have not been used as extensively as dc resistivity methods for groundwater studies because the equipment is more expensive and the interpretation methods are more complicated. These methods are frequently better suited for exploration problems with conductive targets than do resistivity methods.

We describe here the physical basis for the transient sounding technique, point out some advantages and disadvantages of the method, describe several targets of interest for groundwater exploration, and discuss the results of model calculations for these groundwater targets. We pay particular attention to an array where the receiver coil is located at the center of the transmitter loop (central induction or in-loop array). Limitations imposed on the transient sounding method by currently available equipment are discussed.

\section{PHYSICAL BASIS FOR TRANSIENT SOUNDINGS}

Transient EM soundings are made with a receiver and transmitter unit attached to a receiver coil and a large transmitter loop, respectively. The transmitter passes a constant current through the loop which produces a primary magnetic field (Figure 1). The current is quickly turned off, thereby interrupting the primary magnetic field. To satisfy Faraday's law, currents are induced in the ground which instantaneously maintain the primary magnetic field. This current system, which flows in closed paths below the transmitter loop, produces a secondary magnetic field. Changes of the secondary magnetic field with time induce a voltage in the receiver coil located of the center of the transmitter loop. Because the magnitude and distribution of the current intensity depend upon the resistivity of the ground, the voltage gives information about the resistivity of the ground. The locus of the maximum 
amplitude of the induced currents diffuses downward and outward with time, thereby giving information about deeper regions as time increases (Nabighian, 1979). The signal recorded by the receiver is called a transient. Several hundred transients are typically recorded and averaged to reduce the effect of background EM and instrumental noise.

Now consider a layered half-space with geometry applicable to many groundwater problems. Initially the induced currents are concentrated close to the surface of the earth, and the induced voltage is time-invariant and proportional to the near-surface resistivity; this is called the early stage. As time passes and the location of maximum current intensity diffuses downward, the voltage becomes proportional to $t^{-5 / 2}$ and to $\rho^{-3 / 2}$ where $\rho$ is the resistivity of the deepest layer; this is called the late stage. Because the transient decays so quickly with time, it is necessary that the receiver have a wide dynamic range.

The shape of the transient is not directly representative of the geoelectrical section at the sounding location. This point is illustrated by Figure 2 which shows the induced voltage over a two-layered earth when the first-layer resistivity is held constant and the second-layer resistivity varies. The curves were computed using a program developed by Anderson (1981). Initially the curves are flat exhibiting early stage behavior. As time increases the voltage starts to decay more and more rapidly until it finally reaches $t^{-5 / 2}$ behavior in the late stage. Notice that even though the second-layer resistivity changes

\section{TRANSIENT SOUNDING WAVEFORMS}

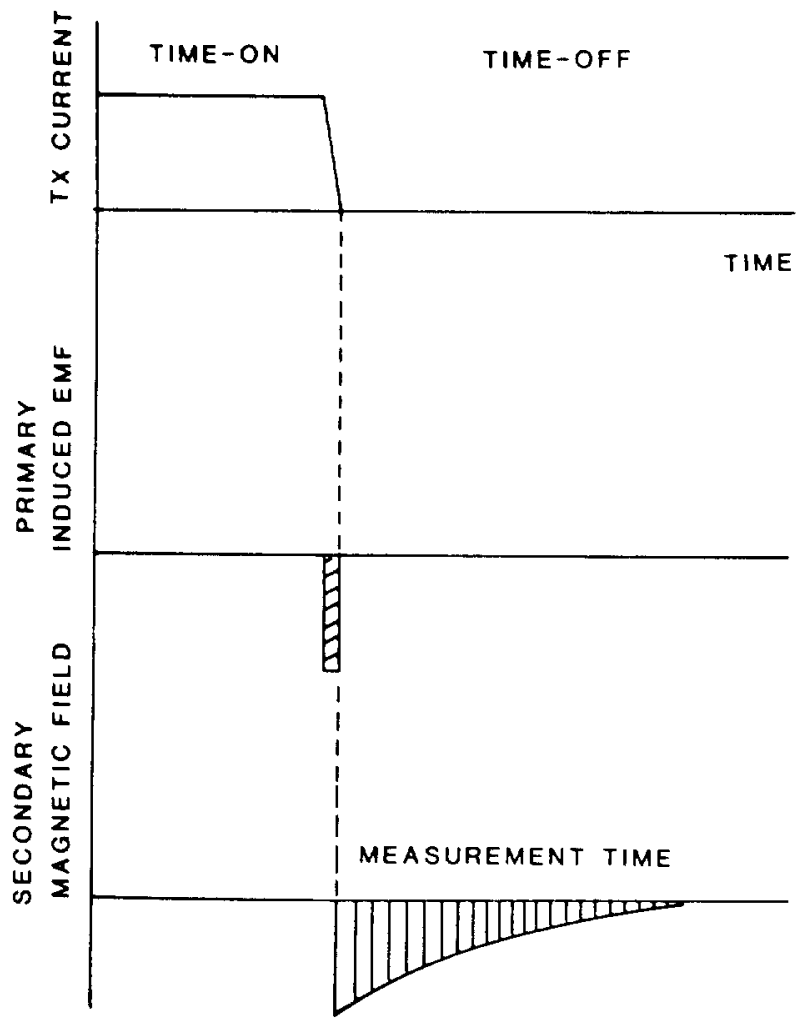

FIG. 1. Transmitter current waveform, induced emf, and secondary magnetic field. The secondary magnetic field is measured during the timeoff. by a factor of 256 , the shape of the induced voltage curves is very similar. To make the curves more representative of the resistivity structure, we convert the voltage curves to apparent resistivity. This is done by comparing the measured voltage to the voltage which would be measured over a half-space of constant resistivity as is done for dc resistivity and magnetotelluric soundings. The apparent resistivity $\rho_{a}$ is given by

$$
\rho_{a} / \rho_{1}=\left|\frac{V_{\mathrm{un}}\left(\rho_{1}, t\right)}{V_{\mathrm{obs}}(t)}\right|^{\lambda},
$$

where $\lambda$ is a real number, $V_{\mathrm{obs}}$ is the observed voltage at time $t$,

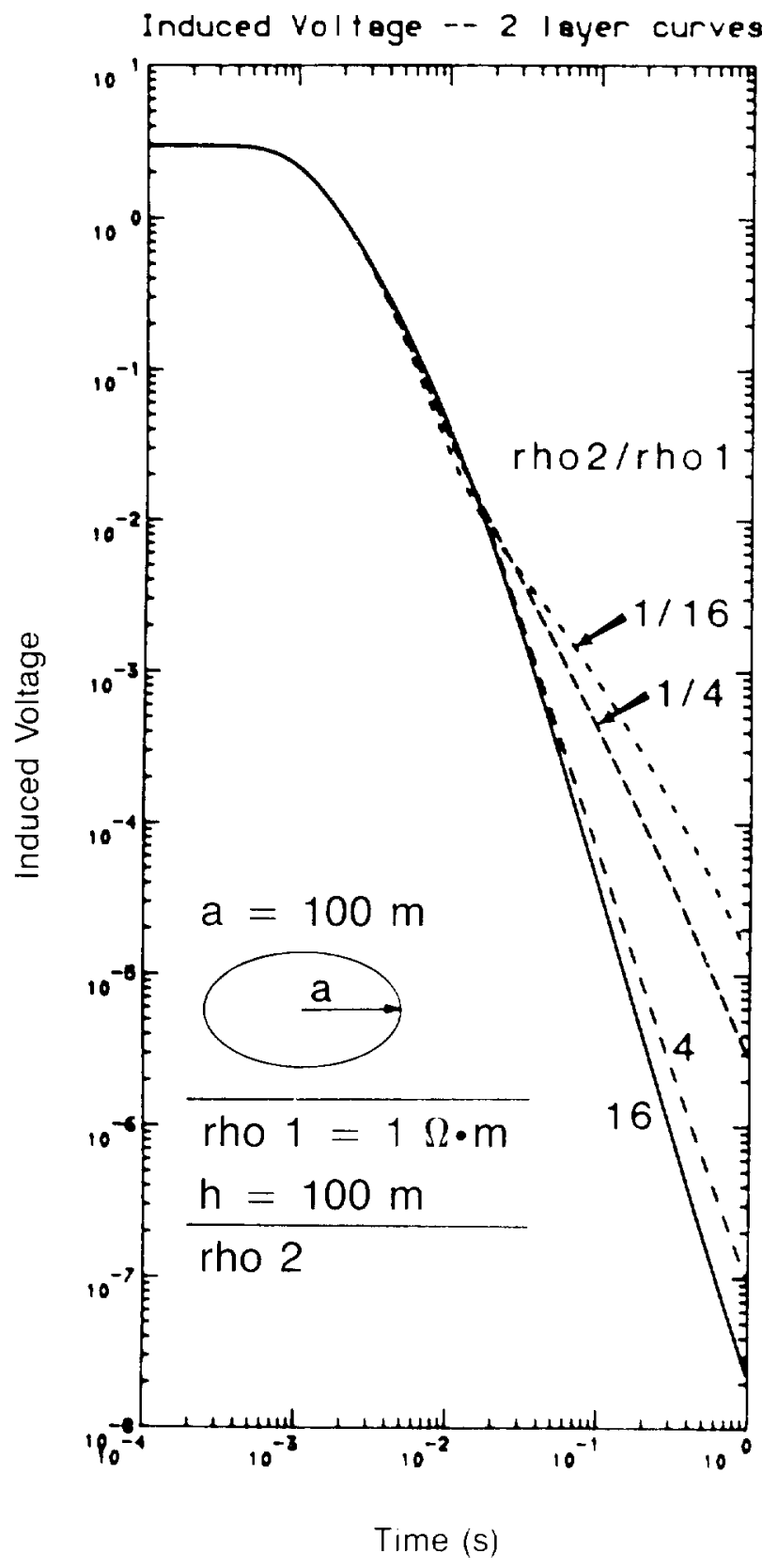

FIG. 2. Induced voltage-time curves for a suite of two-layer models. The first-layer thickness and transmitter loop radius are $100 \mathrm{~m}$. The transmitter current is $1 \mathrm{~A}$, and the receiver loop moment is $1 \mathrm{~m}^{2}$. 
and $V_{\text {un }}$ is the voltage which would be observed over a uniform half-space of resistivity $\rho_{1}$ at time $t$. Notice that we must know the value of $\rho_{1}$ a priori to compute $V_{u n}$. This problem is avoided by assuming the field $V_{\text {un }}$ follows late-stage behavior and by choosing $\lambda=2 / 3$ (Kaufman and Keller, 1983). Then the apparent resistivity becomes

$$
\rho_{a}=\frac{\mu}{4 \pi t}\left|\frac{2 \pi \mu r^{2} M_{r} \mathbf{I}}{5 t V}\right|^{2 / 3},
$$

where $\mu$ is the magnetic permeability, $r$ is the transmitter loop radius, $M_{r}$ is the receiver coil moment, $I$ is the transmitter current, $t$ is the time after current turnoff, and $V$ is the voltage induced in the receiver coil. In practice rectangular loops are used, and the data are analyzed assuming an equal-area circular loop.

Figure 3 shows the apparent resistivity curves computed for the voltage curves shown in Figure 2 for a sequence of twolayered models. The curves are characterized by a descending branch at early time. This portion of the curve does not represent the true resistivity of the ground because we assumed in the apparent resistivity calculation that the field follows latestage behavior at all times. Because this obviously is not true in the early stage, the apparent resistivity is not representative of the true resistivity. There are other apparent resistivity formulations which avoid this problem in the early stage; however, they are more complicated to compute (Spies and Raiche, 1980; Raab and Frischknecht, 1983). In the intermediate and late stages these formulations behave similarly. The apparent resistivity in the central part of the curve approximates the first-layer resistivity provided the first layer is sufficiently thick with respect to the transmitter loop radius. Finally, the apparent resistivity approaches the second-layer resistivity as time increases because at late enough time almost all of the current has diffused into the second layer, effectively making the measurement insensitive to the first-layer resistivity. Consequently, in theory the depth of investigation for transient soundings is a function of time, not loop radius. From a practical point of view, the signal must be sufficiently strong with respect to the background EM and instrumental noise to be measurable. If the signal is too weak to be detected, the transmitter moment must be increased. Increasing the signal by enlarging the transmitter loop affects the sounding curve at early times when the loop radius is greater than the first-layer thickness. Under this situation it is difficult to determine the first-layer parameters.

Looking at theoretical apparent resistivity sounding curves gives the impression that the entire curve can and should be measured in a field situation. Often sufficient information to answer the exploration questions can be obtained from only a portion of the sounding curve. Furthermore, there are two factors which prevent the entire curve from being measured. The first factor limits recording of the earlier part of the sounding curve, while the second affects the later part of the curve.

Because of technical limitations of presently available equipment, sampling of a transient before $100 \mu$ s after current turnoff can be quite difficult. This constraint sets a minimum first-layer thickness necessary to determine the first-layer resistivity. Multilayer resistivity sounding curves have a characteristic minimum $\left(\rho_{2} / \rho_{1}>1\right)$ or maximum $\left(\rho_{2} / \rho_{1}<1\right)$ (see Figure 3) which occurs near

$$
\tau_{1} / h_{1}=\left(2 \pi 10^{7} t \rho_{1}\right)^{1 / 2} / h_{1} \approx 7-11
$$

The value on the right-hand side varies with the ratio of the loop radius to first-layer thickness. Data must be obtained before reaching this value to estimate the first-layer resistivity reliably. For a first layer with a resistivity of $50 \Omega \cdot \mathrm{m}$ or move, $h_{1}$ must be at least $50 \mathrm{~m}$.

The second factor which restricts measurement of a complete transient is EM noise. While commercial equipment now available has a maximum sampling time of several hundred milliseconds after current turnoff, noise considerations limit the length of time during which the transient can be sampled. To determine if the transient response is of sufficient magnitude to be detected we compare it to the ambient noise recorded when the transmitter is not operating. This noise level varies from location to location. However, we can use an average value for planning field operations.

The voltage induced in the receiver coil is the product of the receiver coil moment $M_{r}$ (area times the number of turns) multiplied by the time derivative of the vertical magnetic flux density. The natural noise level of the derivative of magnetic flux density is on the order of $10^{-9} 10^{-10} \mathrm{~V} / \mathrm{m}^{2}$ after passing through the signal processing circuitry of a typical timedomain receiver, although under quiet conditions the level can drop as low as $10^{-11} \mathrm{~V} / \mathrm{m}^{2}$ (D. McNeill, Geonics Ltd., 1985, pers. comm.). (Note that $1 \mathrm{~V} / \mathrm{m}^{2}=1 \mathrm{~W} / \mathrm{m}^{2} / \mathrm{s}$, the usual unit for the time rate of change of the magnetic flux density.) Solving equation (2) for $V / M_{r}$ gives

$$
\begin{aligned}
V / M_{r} & =\frac{2 \pi r^{2} \mu \mathbf{I}}{5 t}\left|\frac{\mu}{4 \pi t \rho_{a}}\right|^{3 / 2} \\
& =\frac{\mu M_{t}}{5 t}\left|\frac{\mu}{4 \pi t \rho_{a}}\right|^{3 / 2},
\end{aligned}
$$

where $M_{t}$ is the transmitter loop moment $\left(M_{t}=2 \pi r^{2} I\right.$ for circular loops or $M_{t}=L^{2} \mathbf{I}$ for square loops where $r$ is the

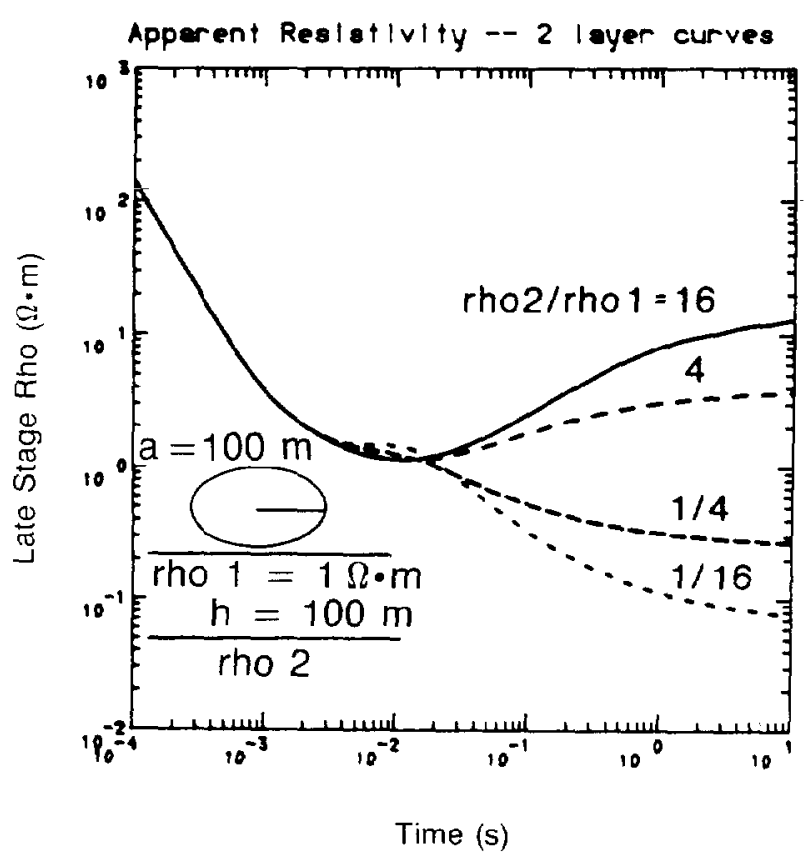

FIG. 3. Late-stage apparent resistivity-time curves for the twolayer models shown in Figure 2. 
radius and $L$ is the length of the side). If we want to determine how much current is required to measure a sounding curve to a particular time, from the sounding curve we determine $\rho_{a}$ at time 1 . Using $p_{u}, t$, the loop size, and the transmitter current, the value of $V / M_{r}$ is computed and compared to the background noise level. If the signal is greater than the noise, there is no difficulty in measuring the transient. If the noise is greater than or equal to the signal level, then the sounding is probably too noisy to use.

Equation (4) gives some important points about transient sounding. Because $V / M_{r}$ is inversely proportional to time, and the induced currents diffuse downward with time, it is more difficult to sound more deeply unless the transmitter moment is increased. To increase the transmitter moment, increase the transmitter current, the leop-area; or beth. The depth of investigation is dependent upon the geoelectrical section. Consider two sounding curves, one with an apparent resistivity $\rho_{a 1}(t)$ and the other $\rho_{a 2}(t)$. If for all $t>t^{*}, \rho_{a 1}$ is greater than $\rho_{a 2}$, then $\left(V / M_{r}\right)_{1}$ will be less than $\left(V / M_{r}\right)_{2}$. This means, for example, that with two two-layered sections with the same firstlayer resistivity, we can sound more deeply with the same current in the section with the more conductive basement. Finally it is important to do some calculations using published or computed sounding curves and cquation (3) before starting field operations, to determine if the survey objectives can be obtained by transient soundings. This can save much time, money, and embarrassment.

While apparent resistivity curves give a general picture of how resistivity varies with depth, the resistivity value at a particular time does not correspond to the actual resistivity value at some depth. For example, in the early stage, the apparent resistivity defined in equation (2) is always greater than the true resistivity. Also for a conductive zone, the apparent resistivity is usually greater than the resistivity of the conductor. The data must be interpreted to obtain the true layer resistivity.

The present level of interpretation capability for transient soundings using layered-earth models is comparable to that of Schlumberger, magnetotelluric (MT), and frequency-domain soundings where interpretation can be done by automatic inversion. However, when necessary, interpretation can be accomplished by curve matching from a catalog of curves. Since 1975 , algorithms for inversion of transient sounding data have been in use (G. V. Keller, 1984, pers. comm.). The NLSTCI program developed by W. L. Anderson (Anderson, 1982) is an excellent example of present-day algorithms which perform nonlinear least-squares parameter estimation using 1-D models for transient soundings. Model parameters are adjusted to obtain the best concordance between the observations and the calculated response of the model in a least-squares sense. Because TS calculations require considerably more computer time than other electrical and EM techniques, it is important that good starting models be found before beginning computer inversion. Catalogs of curves and empirical relationships (Kaufman and Keller, 1983) provide an efficient way of obtaining the initial model. Least-squares inversion methods result in a globally acceptable fit with the errors uniformly distributed among the observations, provided proper weighting of the data is used.

Finding an acceptable solution, however, is only half the problem. The interpretation must address the uncertainty of the model parameter estimates. Suppose we know the apparent resistivity curve with a given precision, and we want to determine the range over which a model parameter can be varied while still keeping the fit within the constraints of the data uncertainty. We can accomplish this by parametric model studies or as an integral part of an inversion scheme (Wiggins, 1972). While determining the parameter ranges, we usually discover that small changes of one parameter can be offset by small changes of another parameter. This is the problem of equivalence which has been studied for other electrical and EM methods. Because our intent is to illustrate the applicability of the TS method for typical groundwater exploration problems, we leave the investigation of the problem of the resolving capability of the TS method for a future study. The problem of equivalence, found in other electrical and EM methods, exists for transient soundings, but at a reduced level (Kaufman and Keller, 1983, p. 549). The state-of-the-art of interpretation is such that this problem can be dealt with on a routine basis.

\section{TS MODEL RESULTS FOR SEVERAL GROUNDWATER PROBLEMS}

We now consider several groundwater exploration problems and show how TS measurements are used to help answer typical questions. These examples illustrate advantages as well as disadvantages of the TS method. The problems discussed are (1) mapping of alluvial fill and gravel zones over bedrock, (2) mapping of sand and gravel lenses in till, (3) detection of salt or brackish water interfaces in fresh water aquifers, and (4) determination of hydrostratigraphy.

\section{Alluvial fill over bedrock}

Alluvium or till often covers bedrock, thereby obscuring the bedrock topography which might control the flow of groundwater. Equally important is the detection of high-porosity gravel zones in the alluvium which serve as fresh water aquifers. A typical exploration problem is to map the depth to bedrock and detect the gravel zone (Figure 4). The alluvium has a resistivity in the range of $50 \Omega \cdot \mathrm{m}$, the bedrock is a low-porosity igneous material with a resistivity of at least 500 $\Omega \cdot \mathrm{m}$, and the gravel zone is a fresh water aquifer with a resistivity of $1000 \Omega \cdot \mathrm{m}$.

First, consider the problem of mapping the thickness of the alluvium. Figure 5 shows the sounding curve computed for a two-layer earth. The first layer has a resistivity of $50 \Omega \cdot \mathrm{m}$ and a thickness of $h_{1}$ which is variable and the bedrock resistivity is $500 \Omega \cdot \mathrm{m}$. In the time range plotted, the left-hand descending branch is not present. The curves have a minimum which becomes very broad and flat, approaching the first-layer resistivity as $h_{1}$ becomes large with respect to the loop radius. At later time, the apparent resistivity asymptotically approaches the basement resistivity. The curves are quite sensitive to the first-layer thickness $h_{1}$ and can be used to map the depth to bedrock. To determine the first-layer resistivity and thickness, the minimum of the sounding curve must be recorded. The time range of present equipment is limited (100 $\mu \mathrm{s}$ to $100 \mathrm{~ms})$, so we can map depth to bedrock only when the alluvium is on the order of $50 \mathrm{~m}$ or more thick and the first-layer resistivity is greater than $50 \Omega \cdot \mathrm{m}$. As described in equation (3), decreasing the first-layer resistivity decreases the minimum depth of exploration.

Effective mapping of bedrock requires a resistivity contrast between the alluvium and the bedrock. In Figure 6 are shown 
soundings where the first-layer thickness and resistivity are fixed while the basement resistivity varies. When there is no contrast between the basement and the overburden, we cannot determine overburden thickness. An example of this would be alluvium over a sedimentary basement such as shale or sandstone where the resistivity might be in the range 5-100 $\Omega \cdot \mathrm{m}$, a range which overlaps with the values commonly found for alluvium. The resistivity contrast would have to be greater than the uncertainty in the measurements if data existed out to the point where the curves approached the second-layer resistivity. $10 \mathrm{~ms}$ in this example. If the apparent resistivity curve ended at an earlier time where the separation in the curves is not as great ( $1 \mathrm{~ms}$ for example), then the resistivity contrast would have to be larger than the measurement uncertainty to be resolvable.

Now let us examine what happens when a high-porosity gravel zone saturated with fresh water is placed below the alluvium (see Figure 4). Assume the $50 \Omega \cdot \mathrm{m}$ alluvium layer is $100 \mathrm{~m}$ thick, the gravel zone has resistivity of $1000 \Omega \cdot \mathrm{m}$ and thickness of $20 \mathrm{~m}$, and the basement resistivity if $500 \Omega \cdot \mathrm{m}$. The results would not be noticeably different from the situation where the fresh water zone was missing. As a result, the depth to bedrock would be underestimated, while the estimated thickness of the alluvium would be accurate.

\section{Sand and gravel lens in till}

High-porosity sand and gravel lenses in till deposits serve as fresh water aquifers. These targets are usually tabular in nature with depth of burial of 20-200 $\mathrm{m}$ and width of $100-$

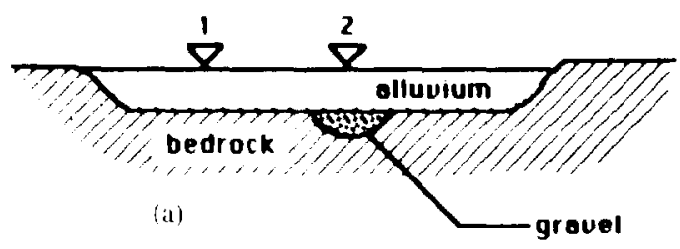

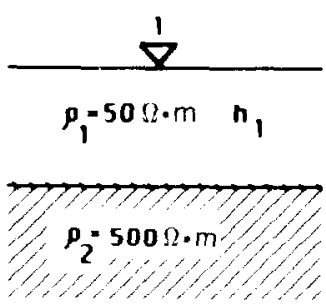

(h)

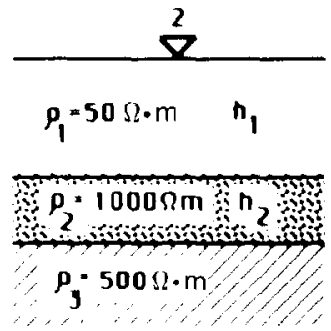

(c)
Fig. 4. Schematic drawing of alluvial fill over bedrock (a) and geolectrical sections at locations where the gravel is (b) and is not (c) present.

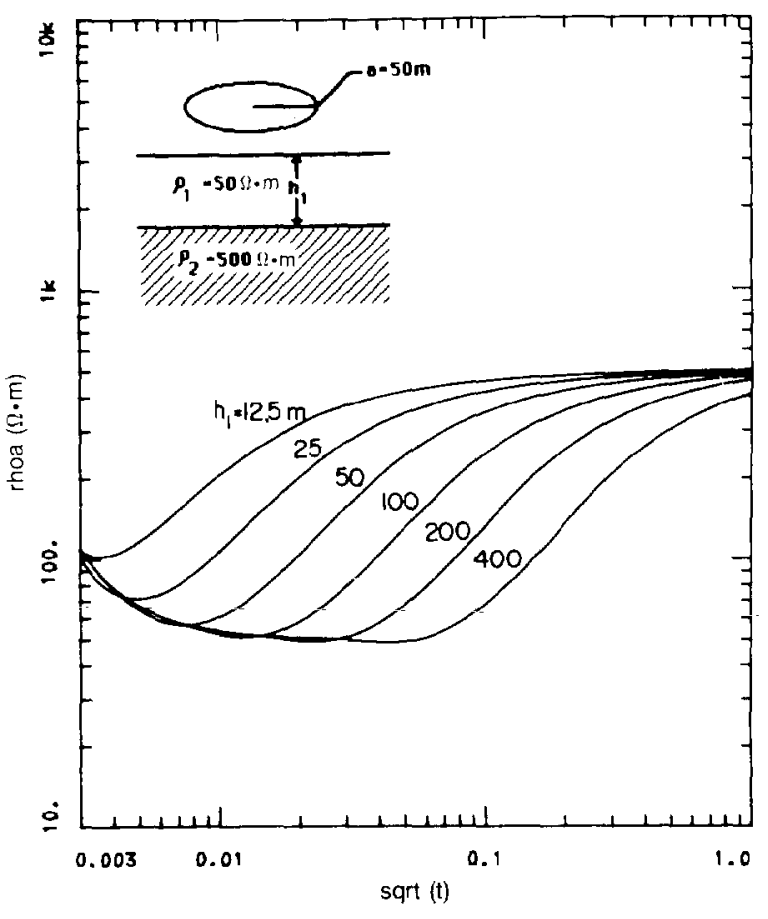

FIG. 5. Transient soundings over alluvial fill showing the effect of varying the fill layer thickness.

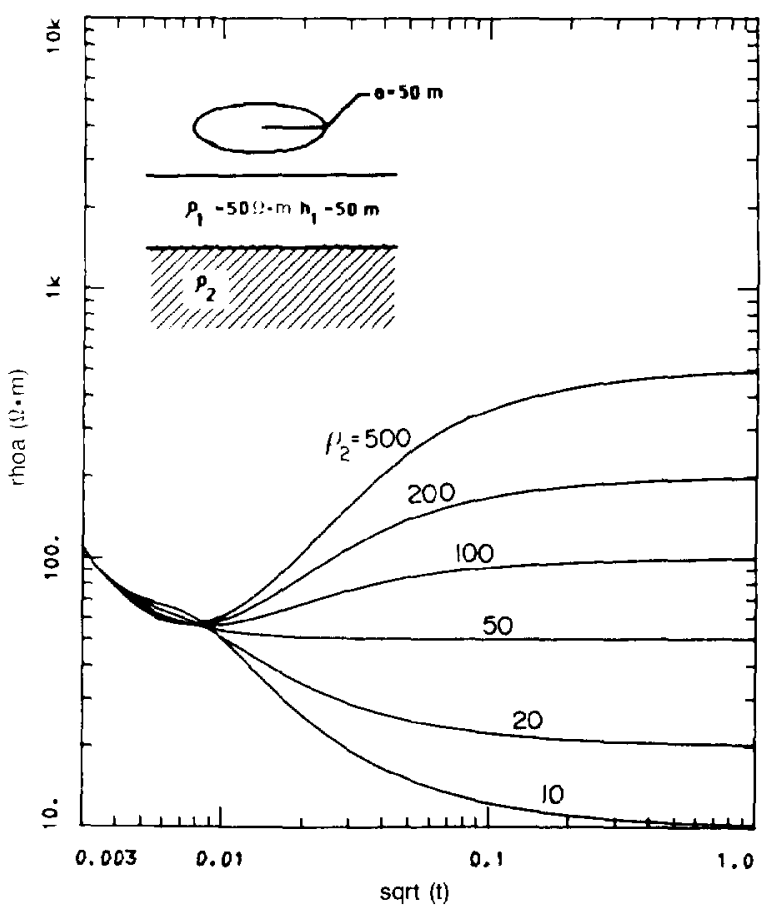

FIG. 6. Transient soundings over alluvial fill showing the effect of varying the basement resistivity. 


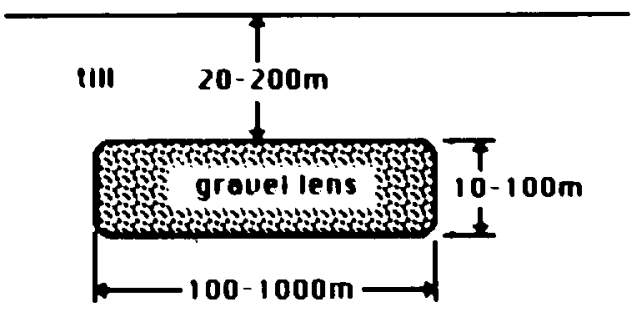

(a)

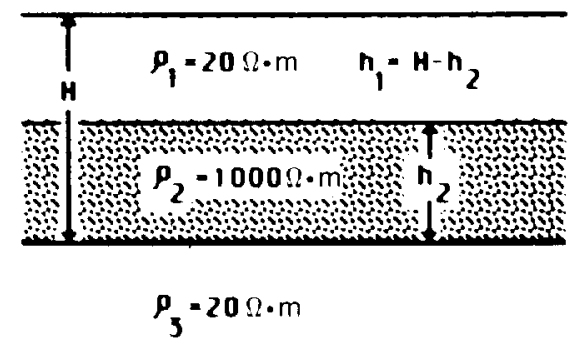

(b)

Fig. 7. Schematic drawing of sand or gravel lens covered by till (a) and the geoelectrical section (b).

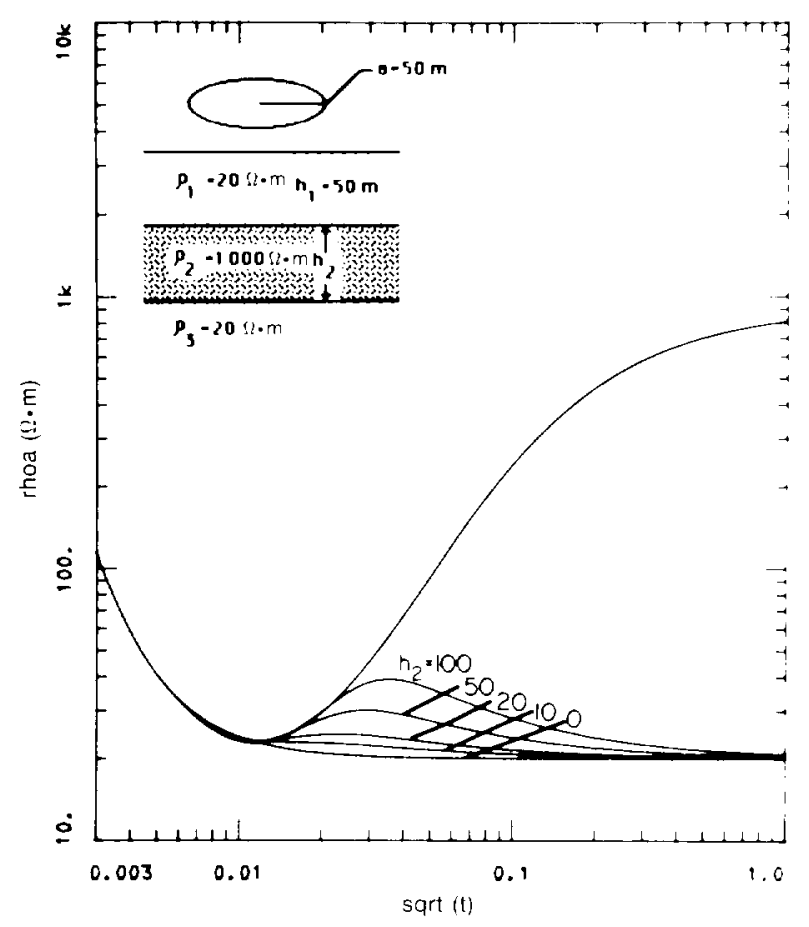

F1G. 8. Transient soundings over till-covered gravel lens showing the effect of varying the lens thickness.
$1000 \mathrm{~m}$ (see Figure 7). For our model calculations we assumed the gravel lens can be modeled by a resistive layer (1000 $\Omega \cdot \mathrm{m}$ ), requiring that the width of the lens be large compared to its depth of burial. The computed sounding curves for several values of lens thickness $h_{2}$ with a till resistivity of $20 \Omega \cdot \mathrm{m}$ are shown in Figure 8. The curves form a family bounded by the homogeneous half-space curve below $\left(h_{2}=0\right)$ and a two-layer curve above $\left(h_{2}=\infty\right)$. The resistive zone causes the apparent resistivity to increase with a maximum magnitude and location being a function of the thickness of the gravel zone. A minimum thickness of at least 10 to $20 \mathrm{~m}$ is necessary to ensure that the zone is detected when buried at a depth of $50 \mathrm{~m}$. Increasing the depth of burial would require a thicker zone. For example, the target thickness would have to increase to more than $20 \mathrm{~m}$ to be detectable at a depth of 100 $\mathrm{m}$.

\section{Salt and brackish water interfaces}

Coastal, fresh water aquifers are often intruded by saltwater from the ocean. The position and movement of this interface influences the location of wells and their rate of production. The TS method provides a good way of siting wells and monitoring salt-water interface migration. Figure 9 shows a crosssection where a salt-water wedge is intruding a coastal aquifer which rests on bedrock. The salt-water layer becomes deeper and thinner in the landward direction. Figure 10 shows the soundings at different distances from the shoreline corresponding to different thicknesses of the salt-water layer. The basement depth is assumed to have a constant depth of $150 \mathrm{~m}$ and a resistivity of $100 \Omega \cdot \mathrm{m}$. The fresh water aquifer has a resistivity of $1000 \Omega \cdot \mathrm{m}$. However, lower resistivities would be expected if the aquifer contained some clay or if water quality were poor. Because the resistivity of the unsaturated zone above the water table will be greater than that of the aquifer, it will not have a significant transient response and can be considered part of the aquifer thickness without changing the results. The thickness of the $5 \Omega \cdot \mathrm{m}$ saltwater layer is varied for the model study. The presence of the salt-water layer changes the position and amplitude of the initial maximum. With a first-layer resistivity of $1000 \Omega \cdot \mathrm{m}$, the maximum will not be recorded because it occurs too early, whereas lower resistivity would shift the maximum to a later time. The apparent resistivity at times greater than the time of the maximum decreases as the thickness of the salt-water layer increases. When the thickness exceeds $10 \mathrm{~m}$, an observable minimum starts to form. Further increase of the salt-water layer thickness results in deepening of the minimum and a shift to later time. This decrease in resistivity is distinct and would allow easy estimation of the depth and thickness of the saltwater layer. Due to equipment constraints, the earlier and later parts of the sounding would not be recorded, so good estimates of the first and last layer resistivity could not be made. This would not pose a problem if the exploration goal were to determine the location and geometry of the salt-water layer.

The TS method has been used on Cape Cod, Massachusetts to map a salt-water interface very similar to the situation shown here (Fitterman and Hoekstra, 1984). The aquifer is composed of clay-free, glacial outwash deposits overlying bedrock and saltwater is encountered at a depth of $80 \mathrm{~m}$ to 120 $\mathrm{m}$. A sounding made near a monitoring well estimated the salt-water layer to be at a depth of $110 \mathrm{~m}$ and the resistive 
basement at $143 \mathrm{~m}$ (Figure 11). The first- and third-layer resistivities were fixed in the inversion because their values could not be estimated accurately from the field data. The difference between the calculated and observed apparent resistivity of the last two data points is due to the finite lateral extent of the salt-water layer which is estimated to terminate $200 \mathrm{~m}$ from the well. The test well was drilled to a depth of $136 \mathrm{~m}$ and never encountered bedrock. Electric logs run in the test well 7 years before the sounding was made detected saltwater at a depth of $99 \mathrm{~m}$.

The previous example showed an unconfined aquifer. A confined aquifer (Figure 12), where the confining zone, a thick clay layer $\left(h_{1}=100 \mathrm{~m}\right)$ with a resistivity of $20 \Omega \cdot \mathrm{m}$, is underlain by a high-porosity zone of thickness $h_{2}$. The highporosity zone is saturated with either fresh water or brine and the aquifer rests upon a crystalline basement. Figure 13 shows the sounding curves over a salt-water saturated aquifer for several aquifer thicknesses. When the aquifer is absent, the sounding curve starts from the early-time asymptote, approaches the first-layer resistivity, and then increases to the basement resistivity at later time. Introducing the salt-water layer produces a noticeable minimum which becomes more pronounced and is shifted to later time as its thickness increases. For the model parameters shown, the minimum detectable thickness for the salt-water layer is about $12.5 \mathrm{~m}$.

When the salt-water layer is replaced by a high-resistivity fresh-water layer, the sounding exhibits very little difference from a two-layer model with a first-layer resistivity of $20 \Omega \cdot \mathrm{m}$ and a basement resistivity of $100 \Omega \cdot \mathrm{m}$ (Figure 14). In fact, the fresh-water layer must be at least $50 \mathrm{~m}$ thick before it can be detected. On the other hand, there is a very noticeable difference between the soundings shown in Figures 13 and 14. The presence of saltwater drastically changes the sounding, indicating that the TS method could be used in this case to map the fresh-water-to-salt-water contact.

\section{Regional hydrostratigraphy}

Hydrostratigraphy refers to the problem of mapping aquifers, confining layers, and basement, as well as to the quality of the water found in the various aquifers. In this case we are concerned with a regional-scale problem where the aquifer covers an area of tens or hundreds of kilometers, with an aquifer thickness of $100-300 \mathrm{~m}$ and a maximum basin depth of $1-2 \mathrm{~km}$. Specifically, consider a hypothetical aquifer similar to the Botucato aquifer in South America (Gilboa et al., 1976).

The Botucatu aquifer is a thick $(300-400 \mathrm{~m})$, TriassicJurassic sandstone covered in some areas by basalt flows. The basalt flows can be as thick as $1500 \mathrm{~m}$. The aquifer is underlain by Permian siltstones, shales, and sandstones (Gilboa et al., 1976), Figure 15 shows a schematic cross-section and geoelectrical section of a hypothetical basin based on the Botucatu. The basalt cover, whose resistivity is quite variable, was assigned a resistivity of $1000 \Omega \cdot \mathrm{m}$, the aquifer $100 \Omega \cdot \mathrm{m}$, and the sediments below the aquifer $20 \Omega \cdot \mathrm{m}$. There are several exploration questions which we would like to answer with transient soundings: (1) the thickness of the basalt cover; (2) the thickness of the aquifer; and (3) the water quality as reflected in the resistivity of the aquifer.

Figure 16 shows the apparent resistivity curves for several first-layer thicknesses. The curves have the typical early-time descending branch, and then continue to descend fairly

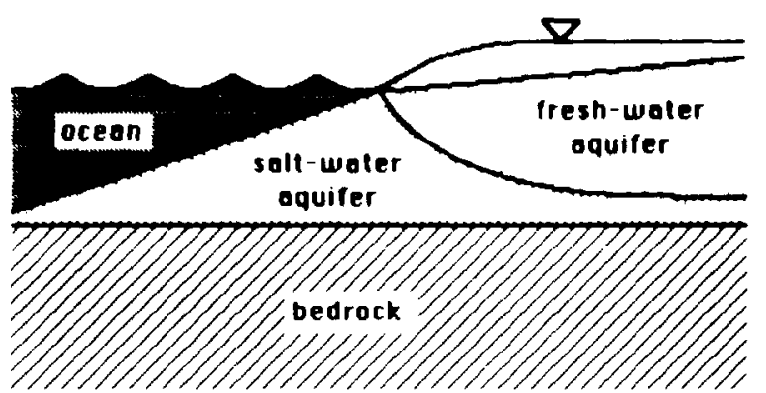

(a)

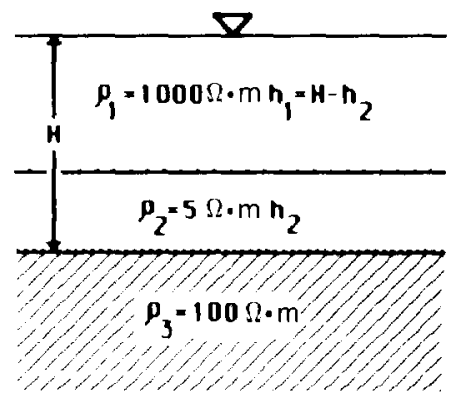

(b)

FIG. 9. Schematic drawing of salt water invading coastal, fresh water aquifer (a) and the geoelectrical section (b).

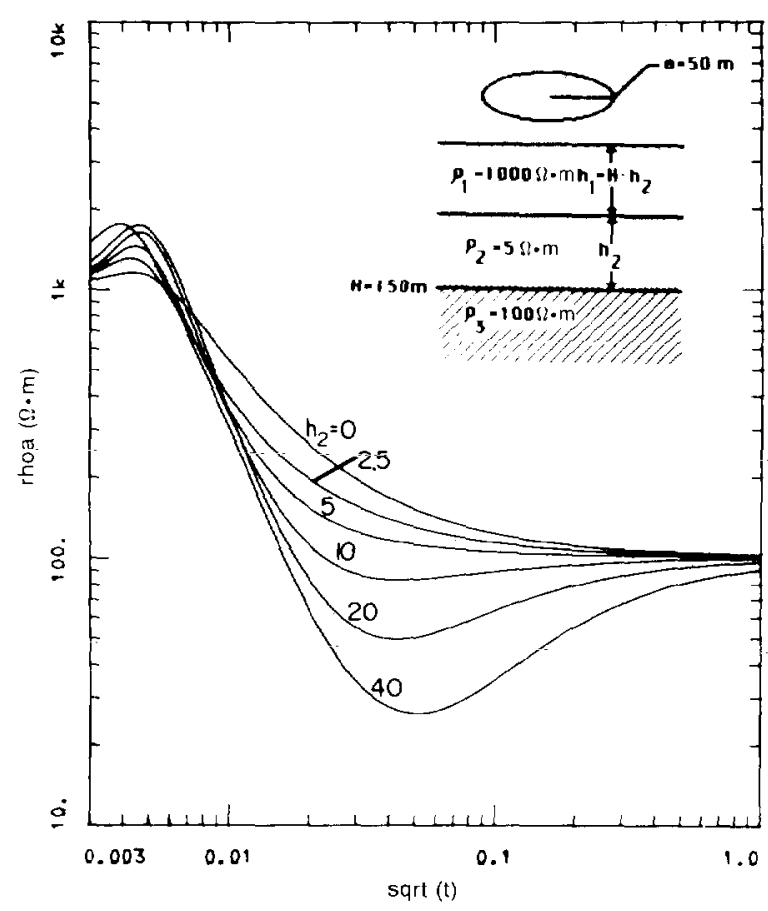

FIG. 10. Transient soundings over an unconfined aquifer with a salt-water zone at the base of the aquifer. The salt-water thickness varies while the depth to bedrock is constant. 


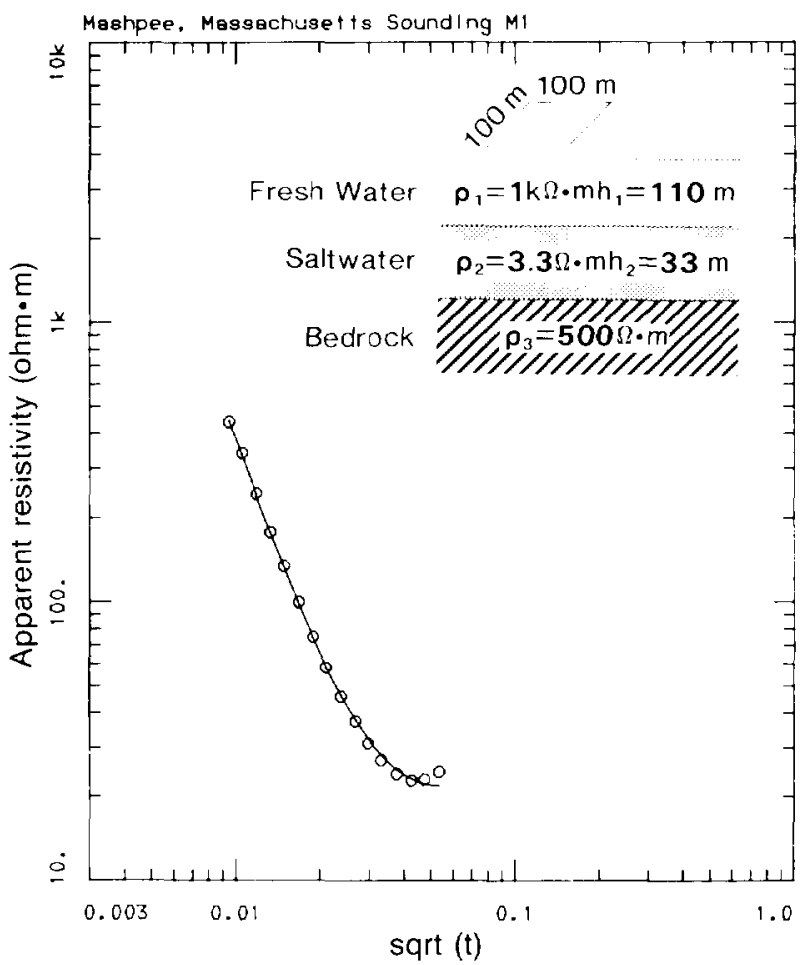

FIG. 11. Transient sounding from Mashpee, MA. The circles are the observed apparent resistivity and the line is the calculated apparent resistivity. The first- and third-layer resistivities were held fixed.

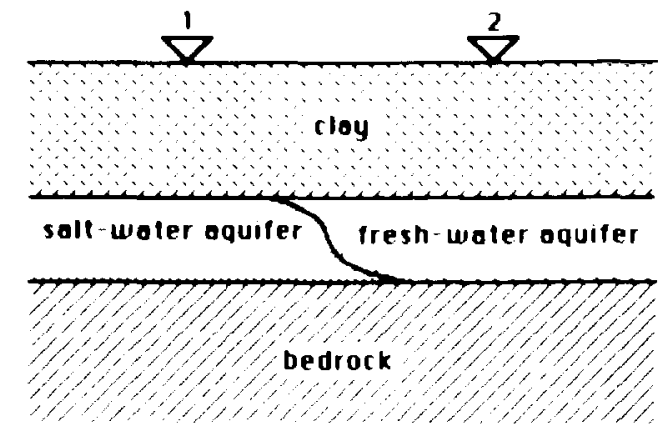

(a)

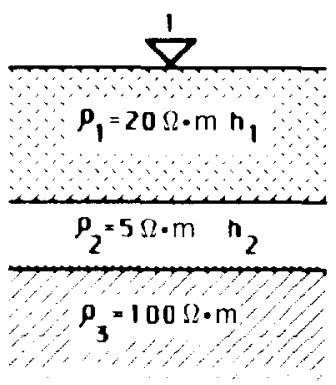

(b)

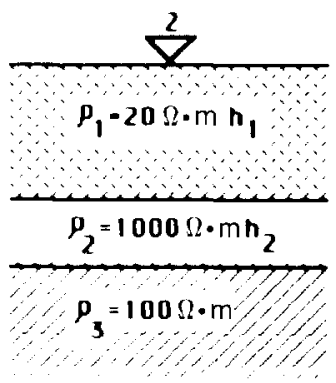

(c)
Fig. 12. Schematic drawing of salt water in a confined aquifer (a) and the geoelectrical sections at locations where the aquifer is saline (b) and fresh (c).

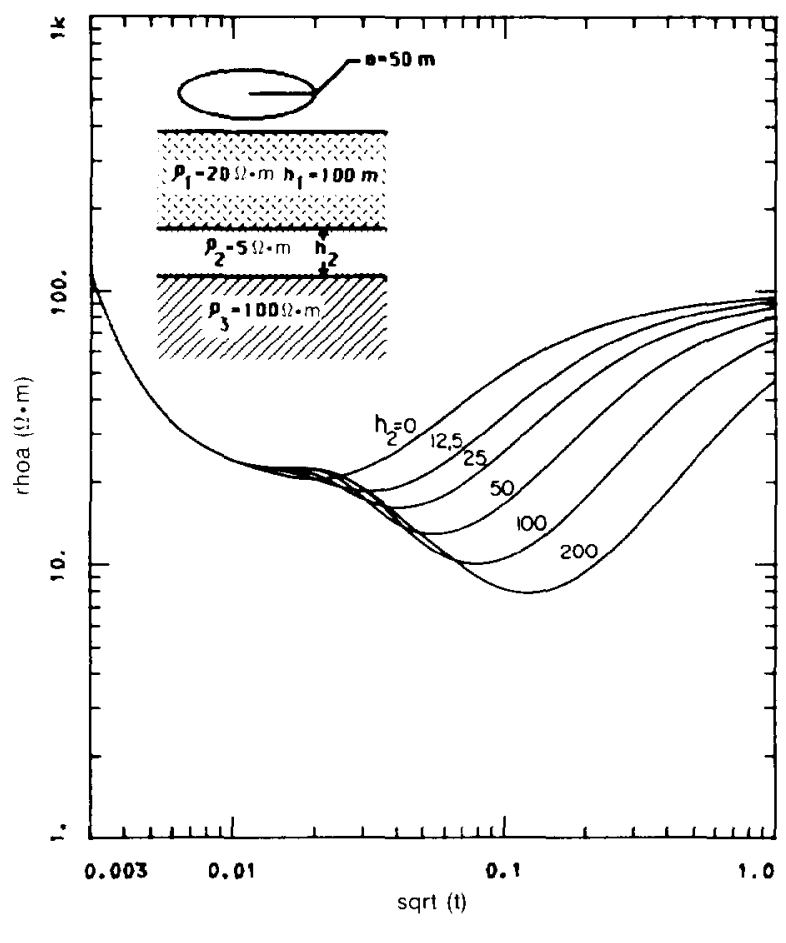

FIG. 13. Transient soundings over a confined aquifer invaded by salt water.

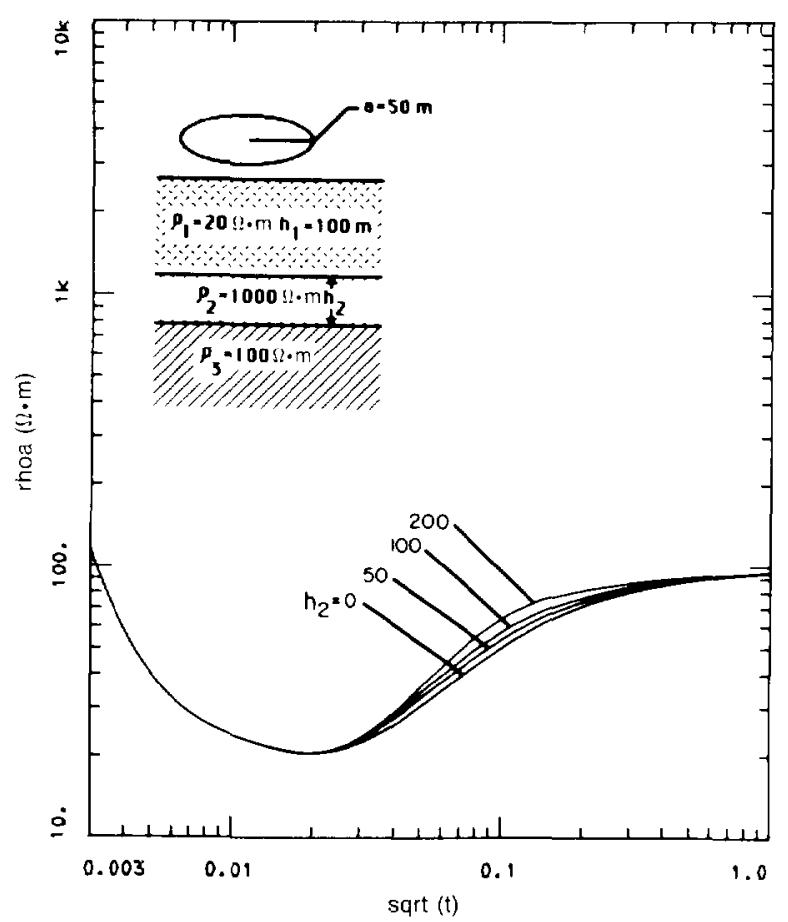

Fig. 14. Transient soundings over a confined, fresh-water aquifer. 
quickly. When the first layer is sufficiently thick, the apparent resistivity approaches the first-layer resistivity, and there is a maximum, whereas when the first layer is thin, the apparent resistivity approaches the second-layer resistivity. Again there is a maximum; however, it occurs later than for the case of a thick first layer. After the maximum the apparent resistivity descends to the basement resistivity in all cases.

The curves show a great deal of separation as a function of first-layer thickness, meaning good estimates of the thickness should be obtainable. The basement resistivity probably will not be well-resolved because the entire transient will not be measurable. Using a detectability level of $10^{9} \mathrm{~V} / \mathrm{m}^{2}$ for the model with $h_{1}=400 \mathrm{~m}$ and a transmitter current of $10 \mathrm{~A}$, the sounding would be measurable to a time of about $10 \mathrm{~ms}$.

Knowing the depth to the aquifer, we must estimate its thickness. Figure 17 shows several curyes for our hypothetical basin. The basalt layer thickness is fixed at $200 \mathrm{~m}$, while the aquifer thickness is allowed to vary. All the curves show a steady decrease in resistivity with time. Varying the aquifer thickness produces a separation of the curves at later time which is smaller than the separation produced by variations in the first-layer thickness. The separation, however, is sufficient to allow estimation of the aquifer thickness.

Figure 18 demonstrates how the sounding curve changes as the aquifer resistivity varies. The curves are characterized by an early-time descending branch followed by a local maxjmum. The location and amplitude of this maximum are greatly dependent upon the aquifer resistivity. The maximum will not be observable because it occurs before measurements begin. A second flexure is formed when the aquifer resistivity is high $(100200 \Omega \cdot \mathrm{m})$. The curves then descend to the base-

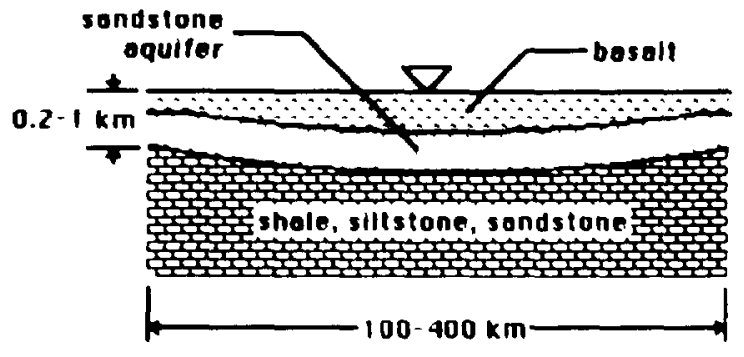

(a)

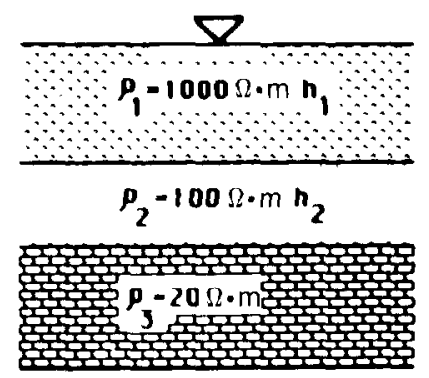

(h)

FIG. 15. Schematic drawing (a) and geoelectrical section (b) of a large regional aquifer.

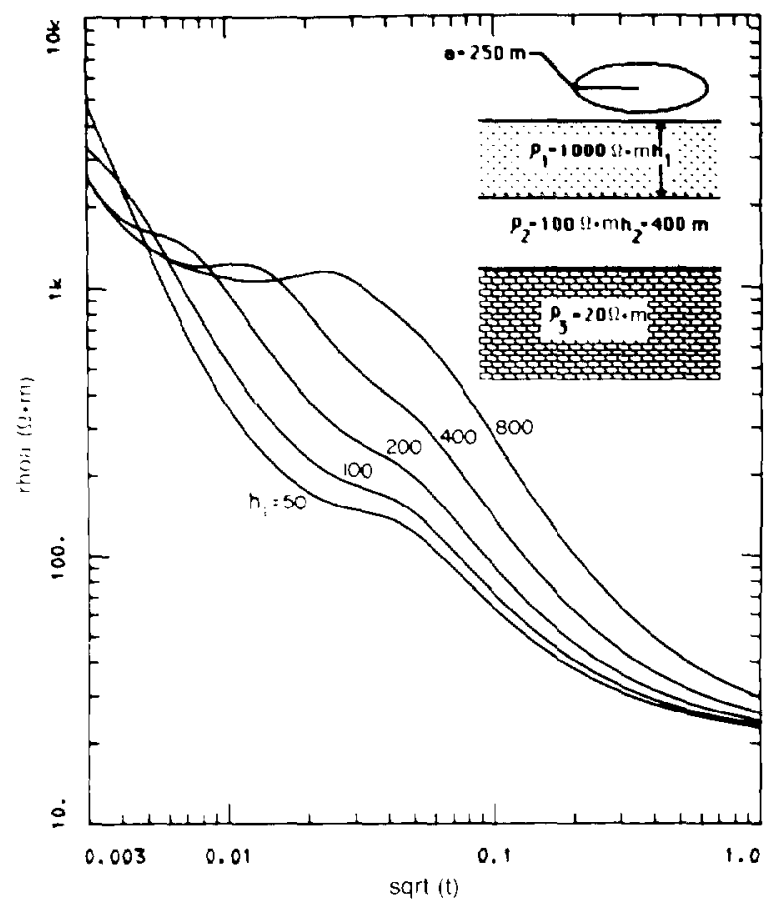

FIG. 16. Transient sounding curves over a regional aquifer showing the effect of varying the first-layer thickness.

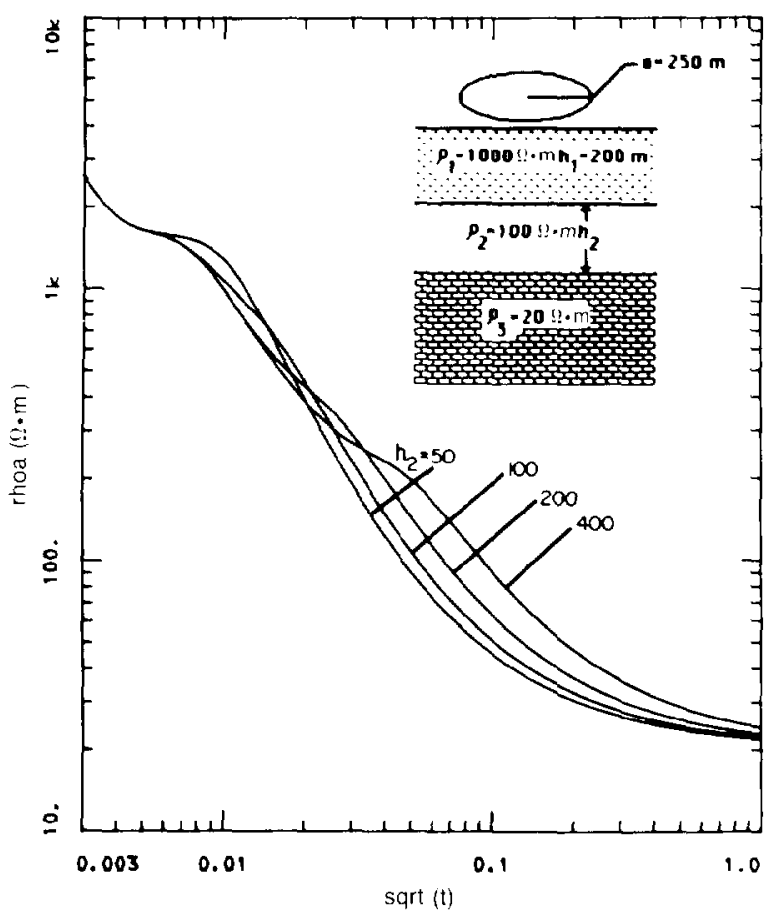

FIG. 17. Transient sounding curves over a regional aquifer showing the effect of varying the aquifer thickness. 
ment resistivity. If the aquifer resistivity is sufficiently less than the basement resistivity a minimum is formed. Changes in the aquifer resistivity are reflected in changes in the apparent resistivity curve; a less resistive aquifer moves the sounding curve downward. Because the soundings show sensitivity to the aquifer resistivity, they will be useful in estimating water quality.

Results of this example show that while we can determine the depth, thickness, and resistivity of the aquifer, we probably cannot determine the resistivity of the first and third layers due to instrumental and noise considerations. Because the main concern of hydrostratigraphic problems is to determine the location, geometry, and water quality of an aquifer, these limitations would not prevent the TS method from being useful.

\section{DISCUSSION}

Model studies of several groundwater targets illustrate the capabilities of the TS method for groundwater exploration. Analysis of mapping the depth to bedrock below alluvium shows that the method has great sensitivity to the thickness of the alluvium, provided the resistivity contrast of the alluvium and the bedrock is greater than the measurement uncertainty. On the other hand, detecting a fresh-water saturated gravel layer at the base of the alluvium would be difficult. The example of mapping a gravel lens in a till demonstrates that while resistive targets can be mapped, they are more difficult to detect than conductive targets. The TS method excels at mapping conductive targets such as a salt-water layer. In the examples, a salt-water layer is easily mapped, even when covered by a thick, conductive clay layer. There is usually a diagnostic difference between soundings made over an aquifer containing

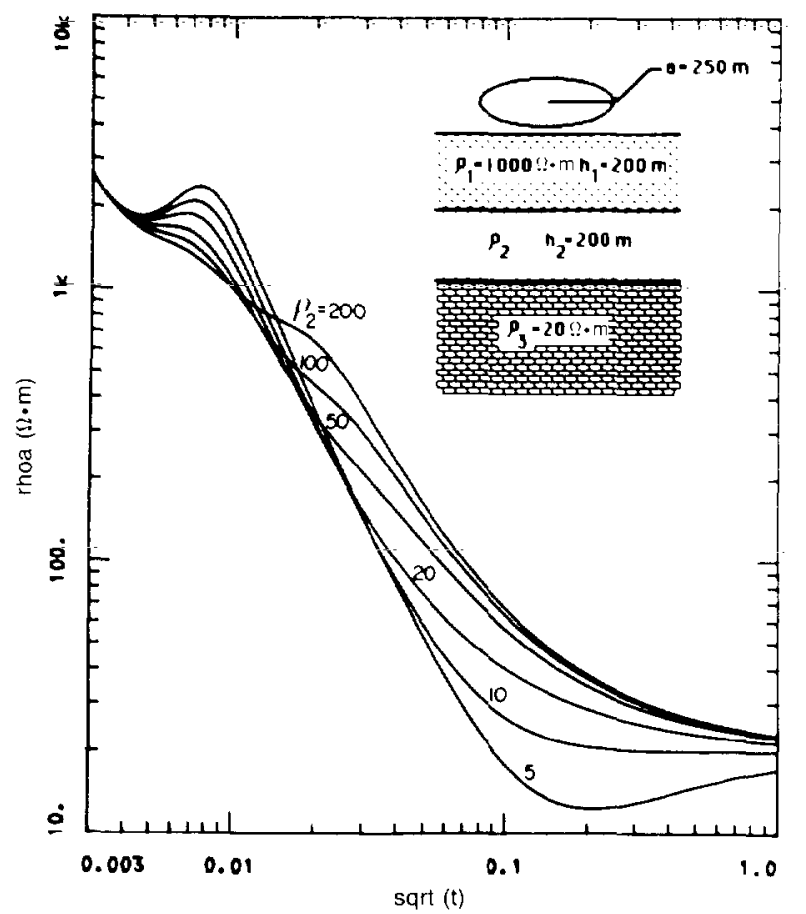

FIG. 18. Transient sounding curves over a regional aquifer showing the effect of varying the aquifer resistivity. salt water and one containing fresh water. The regional hydrostratigraphy example shows how the TS method can be used to map the location, geometry, and water quality of a large aquifer.

In theory the depth of exploration for the TS method is a function of time and does not depend upon the transmitterreceiver separation. In this regard the technique is fundamentally different from Schlumberger and existing frequencydomain EM sounding. In practice, however, noise considerations require that larger transmitter moments be used to produce sufficiently large signals to sound deeply. It is good practice to perform signal strength calculations based upon anticipated geologic conditions before field operations begin to determine the transmitter loop size and current required to obtain the needed information.

The central induction array has low sensitivity to lateral resistivity changes since the induced currents flow in rings around the receiver and thus reduce noise due to small surface inhomogeneities.

The transient sounding technique has an advantage over all dc electrical techniques in that the transmitter inductively couples with the ground. Therefore, contact resistance in resistive terrain is not a concern with regard to the amount of current which can be transmitted.

Currently available equipment which uses the TS method has several disadvantages and limitations which will probably be eliminated with further development. Available equipment has difficulty detecting shallow targets due to the necessity of measuring the transient at very early times. In these situations application of the TS method is currently difficult, and other methods should be considered. TS equipment is complex and expensive. However, when weighed against the quality of the data obtained and the cost of drilling test holes, it is often worth the extra expense. The data interpretation techniques, while similar to those used for Schlumberger soundings, are not widely known. Published catalogs of sounding curves are not widely distributed; however, published programs are available to perform the calculations to make catalogs (Anderson, 1981; Goldman, 1983). In spite of these limitations, the transient sounding technique can and has been used successfully for groundwater studies.

\section{ACKNOWLEDGMENT}

We thank Prof. A. A. Kaufman for many insightful comments and discussions during preparation of this paper.

\section{REFERENCES}

Anderson, W. L., 1981, Calculation of transient soundings for a central induction loop system (Program TCILOOP): U.S. Geol. Surv. open-file rep. 81-1309.

- 1982, Nonlinear least-squares inversion of transient soundings for a central induction loop system (program NLSTCI): U.S. Geol. Surv. open-file rep. 82-1129.

Bonini, W. E., and Hickok, E. A., 1969, Seismic refraction method in ground-water exploration: Am. Inst. Min., Metallurg., Petr. Eng. Trans., 211, 485-488.

Carmichael, R. S., and Henry, G., Jr., 1977, Gravity exploration for groundwater and bedrock topography in glaciated areas: Geophysics, 42, 850-859.

Eaton, G. P., and Watkins, J. S., 1970. The use of seismic refraction and gravity methods in hydrogeological investigations, in Morley, L. W., Ed., Mining and groundwater geophysics: Geol. Surv. Can., Economic Geol. Rep. 26, 544-568. 
Fitterman, D. V., and Hoekstra, P., 1984, Mapping of saltwater intrusion with transient electromagnetic soundings, in Nielsen, D. M. and Curl M., Eds., Proceedings of the National Water Well Assn. conference on surface and borehole geophysical methods in subsurface investigations, San Antonio: National Water Well Assn., 429 454.

Flathe, H., 1955, Possibilities and limitations in applying geoelectrical methods to hydrogeological problems in the coastal areas of northwest Germany: Geophysical Prosp., 3, 95-110.

- 1970, Interpretation of geoelectrical resistivity measurements for solving hydrogeological problems, in Morley, L. W., Ed., Mining and groundwater geophysics: Geol. Surv. Can. Economic Geol. Rep. 26, 580-597.

Gilboa, Y., Mero, F., and Mariano, I. B., 1976, The Botucatu aquifer of South America, model of an untapped continental aquifer: J. Hydrology, 29, 165-179.

Goldman, M. M., 1983, The integral-finite-difference method for calculating transient electromagnetic fields in a horizontally stratified medium: Geophys. Prosp., 31, 664-686.

Hall, D. H., and Hajnal, Z., 1962, The gravimeter in studies of buried valleys: Geophysics, 27, 939-951.

Kaufman, A. A., and Keller, G. V., 1983, Frequency and transient soundings: Elsevier Science Publishers.

Levshin, A. L., 1961, Determination of ground-water level by the seismic method: Akad. Nauk SSSR Izv. Ses. Geofiz., 9, 857-870
Nabighian, M. N., 1979, Quasi-static transient response of a conducting half-space-An approximate representation: Geophysics, 44, $1700-1705$.

Ogilvy, A. A., 1970, Geophysical prospecting for groundwater in the Soviet Union, in Morley, L. W., Ed., Mining and groundwater geophysics: Geol. Surv. Can., Economic Geol. Rep. 26, 536-543.

Raab, P. V., and Frischknecht, F. C., 1983, Desktop computer processing of coincident and central loop time domain electromagnetic data: U.S. Geol. Surv, open-file rep. 83-240.

Spangler, D. P., and Libby, F. J., 1968, Application of the gravity survey method to watershed hydrology: Ground Water, 6, 21-26.

Spies, B. R., and Raiche, A. P., 1980, Calculation of apparent conductivity for the transient electromagnetic (coincident loop) method using an HP-67 calculator: Geophysics, 45, 1197-1200.

Stewart, M. T., 1982, Evaluation of electromagnetic methods for rapid mapping of salt-water interfaces in coastal aquifers: Ground Water, $20,538-545$

Wiggins, R. A., 1972, The generalized inverse problem: Rev. Geophys. Space Phys., 10, 251-286.

Zohdy, A. A. R., 1969, The use of Schlumberger and equatorial soundings in groundwater investigations near El Paso, Texas: Geophysics, 34, 713-728.

Zohdy, A. A. R. Eaton, G. P. and Mabey, D. R., 1974, Application of surface geophysics of ground-water investigations: U.S.G.S. Techniques of Water-Resources Investigations, Book 2, chap. D1. 